\title{
Edukasi Konsep dan Produk Koperasi Syariah pada Kelompok Pengajian Masjid Al-Hikmah Desa Tanimulya Kecamatan Ngamprah Kabupaten Bandung Barat
}

\author{
Bambang Wisnuadhi ${ }^{1}$, Setiawan ${ }^{2 *}$, Ghifari Munawar ${ }^{3}$, Hasbi Assidiki Mauluddi ${ }^{4}$, \\ Dimas Sumitra Danisworo ${ }^{5}$ \\ 1,3 Jurusan Teknik Komputer dan Informatika, ${ }^{2,4,5}$ Jurusan Akuntansi \\ Politeknik Negeri Bandung - Jalan Gegerkalong Hilir, Desa Ciwaruga, Bandung 40012 \\ *e-mail corresponding author : setiawan@ polban.ac.id. No. HP. +628999008809
}

\begin{abstract}
ABSTRAK
Islam merupakan agama dengan penganut terbanyak di Indonesia, namun sampai saat ini umat Islam belum bisa mendominasi perekonomian. Penguasaan sektor ekonomi baru mencapai 12 persen oleh Muslim di Indonesia. Padahal umat Islam memiliki wadah pendidikan yang baik untuk bisa memulai bahkan mengaplikasikan kegiatan ekonomi secara praktis yaitu melalui majelis taklim. Para penceramah di majelis taklim harus memulai memberikan materi yang bermuatan ekonomi seperti pembangunan koperasi yang berbasis syariah. Untuk bisa menjalankan koperasi syariah tentunya harus didahului pemahaman terhadap produk berbasis syariah yang mungkin bisa dikembangkan di koperasi syariah. Masih banyak peserta pengajian di Masjid Al-Hikmah Desa Tanimulya, Kecamatan Ngamprah, Kabupaten Bandung Barat yang belum memahami mengenai konsep koeprasi syariah dan juga produk-produk di koperasi syariah. Untuk mengatasi permasalaham tersebut Tim Pengabdian Kepada Masyarakat Politekni Negeri Bandung memberikan edukasi mengenai konsep dan produk-produk koperasi syariah. Peserta yang hadir pada kegiatan Pengabdian Kepada Masyarakat (PKM) ini berjumlah 20 orang. Metode yagn digunakan adalah dengan ceramah dan diskusi. Setelah selesai kegiatan maka dilakukan evaluasi teknis dan pengukuran tingkat pemahaman. Melalui uji beda Wilcoxon Signed Rank Test diperoleh hasil bahwa kegiatan ini sangat bermanfaat karena mampu meningkatkan pemahaman peserta. Dengan Kegiatan Pengabdian Kepada Masyarakat (PKM) melalui ceramah dan diskusi ini diharapkan kelompok pengajian Al-Hikmah dapat menjadikan pemahaman yang diperolehnya untuk mendirikan koperasi syariah.
\end{abstract}

Kata kunci : koperasi syariah; konsep koperasi syariah; produk koperasi syariah

\section{ABSTRACT}

Islam is the religion with the most adherents in Indonesia, but until now Muslims have not been able to dominate the economy. Economic control has only reached 12 percent by Muslims in Indonesia. Whereas Muslims have a good place for education to be able to start and even apply economic activities practically through the taklim assembly. The speakers at the majelis taklim must start giving material that is economically charged such as the construction of sharia-based cooperatives. To be able to run a sharia cooperative, of course, it must be preceded by an understanding of sharia-based products that might be developed in sharia cooperatives. There are still many study participants at the Al-Hikmah Mosque in Tanimulya Village, Ngamprah District,

Cara Mengutip : Wisnuadhi, B., Setiawan, S., Munawar, G., Mauluddi, H. A., Danisworo, D.S. (2020). Edukasi Konsep dan Produk Koperasi Syariah pada Kelompok Pengajian Masjid Al-Hikmah Desa Tanimulya Kecamatan Ngamprah Kabupaten Bandung Barat. JAST: Jurnal Aplikasi Sains dan Teknologi, 4 (1), 44-51. doi:http://dx.doi.org/10.33366/jast.v4i1.1569 
West Bandung Regency who do not understand the concept of sharia co-operation and also products in sharia cooperatives. To overcome these problems, the Community Service Team of the Politeknik Negeri Bandung provides education on the concepts and products of Islamic cooperatives. There were 20 participants attending the Community Service Activities (PKM). The method used is lectures and discussions. After completing the activities, a technical evaluation and measurement of understanding are carried out. Through the Wilcoxon Signed Rank Test different results obtained that this activity is very useful because it can increase the understanding of participants. With Community Service Activities (PKM) through lectures and discussions, it is expected that the Al-Hikmah study group can make the understanding it gets to establish a sharia cooperative.

Keywords : islamic cooperatives; the concept of islamic cooperatives; islamic cooperative products

\section{PENDAHULUAN}

Indonesia merupakan negeri dengan mayoritas penganut agama Islam dan telah menyumbang populasi Muslim dunia terbesar dengan persentase 12,6 persen [1]. Menurut studi Pew Research Institute diperkirakan pada 2070 Islam akan menjadi agama mayoritas mayoritas di dunia [2], [3]. Masih dalam studi yang sama, disebutkan bahwa di Indonesia sendiri Muslim mendominasi sekitar 87\% populasi penduduk Indonesia. Dengan potensi yang sangat besar tersebut, seharusnya Muslim bisa memiliki peran yang signifikan ketika berada di tengahtengah masyarakat [4], [5]. Namun sampai sekarang umat Muslim di Indonesia belum bisa memberikan pengaruh yang besar bagi kehidupan masyarakat khususnya dalam bidang ekonomi. Hal ini terlihat dari penguasaan sektor ekonomi yang baru sebatas 12 persen oleh Muslim di Indonesia [6].

Padahal umat Islam memiliki sarana yang baik untuk menciptakan masyarakat yang dapat mengantarkan pada kemakmuran atau falah bersama, yaitu majelis taklim. Majelis taklim ini merupakan sarana dakwah yang memiliki peran sangat penting dalam pembinaan dan peningkatan kualitas hidup umat Islam sesuai tuntunan ajaran Islam [7]. Berasal dari majelis taklim-lah, umat Islam mendapatkan pengetahuan dan pemahaman dalam penerapan kehidupan beragama, baik untuk masalah ibadah maupun masalah dunia (ekonomi, sosial, dan lainnya) atau biasa disebut muamalah. Masyarakat yang secara rutin mengikuti kegiatan keagamaan seperti majelis taklim ini akan memberikan dampak terhadap perilaku mereka yang sesuai dengan tuntunan agama [8].

Namun sangat disayangkan bahwa sarana tersebut tidak dimanfaatkan oleh umat Islam untuk dapat mengentaskan kemiskinan dan melakukan pemberdayaan terhadap mereka yang terbelakang. Karena masih banyak bagian dari dunia Muslim yang tertinggal secara teknologi dan ekonomi [9]. Hal ini sulit terwujud karena sebagian besar penceramah yang memberikan materi di majelis taklim jarang membahas tema-tema terkait teknologi maupun ekonomi. Mereka lebih cenderung membawakan tema yang menguak hubungan manusia dengan Tuhannya, sedangkan hubungan manusia dengan manusia lainnya dan hubungan manusia dengan alam jarang dibahas. Padahal semua kegiatan bisa dikaitkan sebagai tu- 
juan ibadah kepada Tuhannya. Sehingga perlu dilakukan dakwah yang bersifat kontekstual, bukan hanya yang bersifat tekstual, yang artinya perlu ada penyampaian materi yang memang benar-benar dibutuhkan secara aplikatif oleh masyarakat secara langsung [10].

Saat ini, sangat dibutuhkan tuntunan bagi masyarakat dari sisi ekonomi agar umat Islam tidak hanya menjadi buih. Padahal kegiatan ekonomi ini dapat menjadi nilai ibadah juga pelakunya bila berlandaskan nilai-nilai Ketuhanan. Dominasi penguasaan ekonomi umat Islam bisa dilihat pula dari perkembangan perbankan syariah yang mendominasi di antara industri syariah yang lain. Sampai Mei 2019, industri perbankan syariah hanya mampu mencatatkan market share sebesar 5,85\%, bahkan sedang melambat dibanding akhir tahun 2018 [11]. Jumlah ini sangat jauh dibanding market share bank konvensional. Hal ini berangkat dari pemahaman ataupun persepsi umat Islam yang menganggap bank syariah sama saja dengan bank konvensional. Dengan kata lain, tingkat literasi masyarakat terhadap keuangan syariah belum mumpuni. Direktur Eksekutif Institute for Development of Economics and Finance (INDEF) Tauhid Ahmad mengatakan "memang masyarakat pada dasarnya sudah tahu namun belum memahami secara utuh keuangan syariah. Untuk itu diperlukan pengembangan literasi keuangan syariah secara holistik dan sederhana" [12]. Hal ini menjadi tantangan bagi para penceramah untuk ikut mencerdaskan umat Islam.

Melalui dakwah yang bersifat kontekstual, penceramah atau mubaligh bisa mengarahkan umat Islam untuk memulai mempraktikkan pengetahuan keuangannya di masyarakat. Seperti dengan mendirikan koperasi syariah, atau bila telah ada, maka uamt Islam harus menghidupkan koperasi tersebut sehingga dapat menjadi penggerak perekonomian para anggotanya ataupun masyarakat sekitar. Dengan demikian, upaya pemberdayaan ekonomi masyarakat harus dimulai dari majelis taklim dan digerakkan bersama-sama oleh umat Islam. Prasyarat mutlak hal tersebut tentunya adalah pertama-tama dengan meningkatnya pemahaman masyarakat terhadap literasi keuangan syariah. Hal ini yang ingin dicapai oleh tim Pengabdian Kepada Masyarakat Politeknik Negeri Bandung yang melihat potensi pemberdayaan di Desa Tanimulya, Kecamatan Ngamprah, Kabupaten Bandung Barat. Terdapat salah satu masjid yang bernama Al-Hikmah di kawasan Puri Cipageran Indah 2 dengan kelompok pengajian perempuan yang cukup besar, namun mereka menggerakkan koperasi yang masih konvensional.

\section{METODE KEGIATAN}

Kegiatan pengabdian kepada masyarakat ini merupakan upaya peningkatan pengetahuan kelompok pengajian perempuan (ibu-ibu) terhadap konsep koperasi syariah serta produk-produk yang mungkin bisa dikembangkan pada koperasi syariah. Peserta dari kegiatan ini tentunya ibu-ibu pengajian di Masjid AlHikmah di kawasan Puri Cipageran Indah 2, Desa Tanimulya, Kecamatan Ngamprah, Kabupaten Bandung Barat.

Secara umum metode yang digunakan pada kegiatan ini adalah dengan cera- 
mah dan diskusi. Komunikasi dibuat dua arah agar audiens atau peserta dapat secara langsung bertanya dan berpendapat di tengah-tengah acara. Sehingga acara dapat berlangsung lebih rileks dan menjadi interaktif. Adapun langkah-langkah dalam pelaksanaan kegiatan ini adalah sebagai berikut:

\section{- Pra kegiatan}

Sebelum kegiatan PKM dilaksanakan, maka tim melakukan studi pendahuluan unutk melihat kebutuhan kelompok pengajian Al-Hikmah tersebut. Setelah itu tim mempersiapkan materi yang akan disampaikan, slide presentasi, dan alat peraga yang akan ditampilkan pada saat kegiatan.

- Pelaksanaan kegiatan

Kegiatan dilaksanakan pada dua kali pertemuan. Pertemuan pertama melakukan penyampaian materi mengenai pengenalan koperasi syariah seperti pengertian, prinsip, tujuan, konsep koperasi syariah. Sedangkan pada pertemuan kedua menyampaikan materi mengenai akad produk-produk yang bisa diaplikasikan atau dikembangkan di koperasi syariah beserta contoh penerapannya.

- Evaluasi kegiatan

Setelah kegiatan dilaksanakan, tim melakukan diskusi untuk mengevaluasi jalannya kegiatan baik secara teknis maupun evaluasi berdasarkan tingkat pemahaman peserta. Adapun tingkat pemahaman peserta diukur melalui pengisian kuesioner yang dilakukan pada saat sebelum kegiatan dan setelah kegiatan. Pengujian statistik yang dilakukan adalah menggunakan uji beda dengan langkah-langkah sebagai berikut: a. Pengujian normalitas dengan menggunakan uji Shapiro Wilk dan Lilliefors. Pengujian ini dipilih karena data sampel yang digunakan tidak terlalu besar.

b. Bila hasil pengujian normalitas menunjukkan bahwa data berdistribusi normal maka uji komparasif dilakukan dengan uji parametris yaitu uji paired $t$ test. Namun bila data yang dihasilkan ternyata memiliki distribusi yang tidak normal maka selan-jutnya akan dilakukan uji nonpara-metris yaitu menggunakan Wilcoxon Signed Rank Test.

c. Pengujian hipotesis antara tingkat pemahaman peserta sebelum kegiatan dan tingkat pemahaman peserta setelah kegiatan. Adapun hipotesis yang dapat diajukan adalah sebagai berikut:

\section{$H_{1}$ : Apakah terdapat perbedaan tingkat pemahaman peserta antara sebelum kegiatan dan setelah kegiatan.}

\section{KARYA UTAMA}

Kegiatan Pengabdian Kepada Masyarakat dengan tema "Edukasi Konsep dan Produk Koperasi Syariah pada Kelompok Pengajian Masjid Al-Hikmah Desa Tanimulya Kecamatan Ngamprah Kabupaten Bandung Barat" ini dilaksanakan pada hari Sabtu tanggal 12 Oktober 2019. Peserta PKM adalah kelompok pengajian Al-Hikmah yang merupakan masyarakat yang berada di sekitar Desa Tanimulya Kecamatan Ngamprah Kabupaten Bandung Barat. 


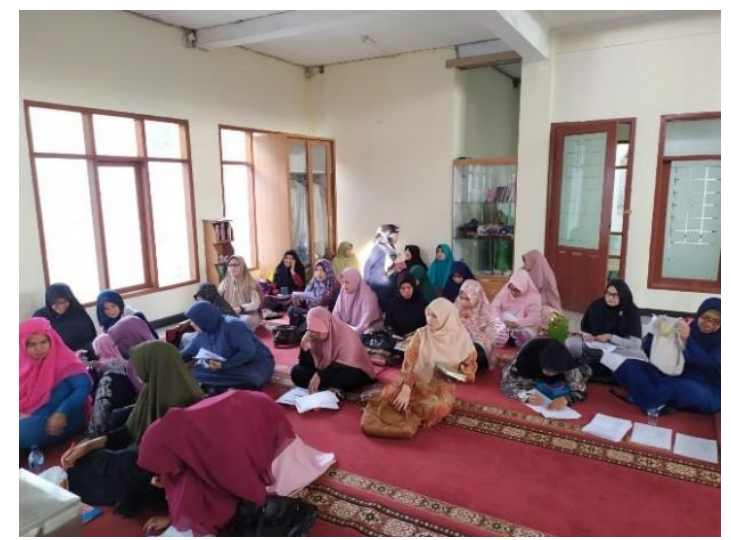

Gambar 1. Kelompok Pengajian Masjid Al-Hikmah Desa Tanimulya

Pada saat pelaksanaan, jumlah peserta sebanyak 20 orang. Pelaksanaan PKM dilakukan bertepatan dengan jadwal rutin pengajian agar ke depannya materi semacam ini dapat terus disampaikan oleh penceramah-penceramah yang biasa mengisi materi di pengajian. Selain itu, pemilihan waktu ini untuk mempermudah sasaran kegiatan agar tidak perlu melakukan penjadwalan secara khusus.

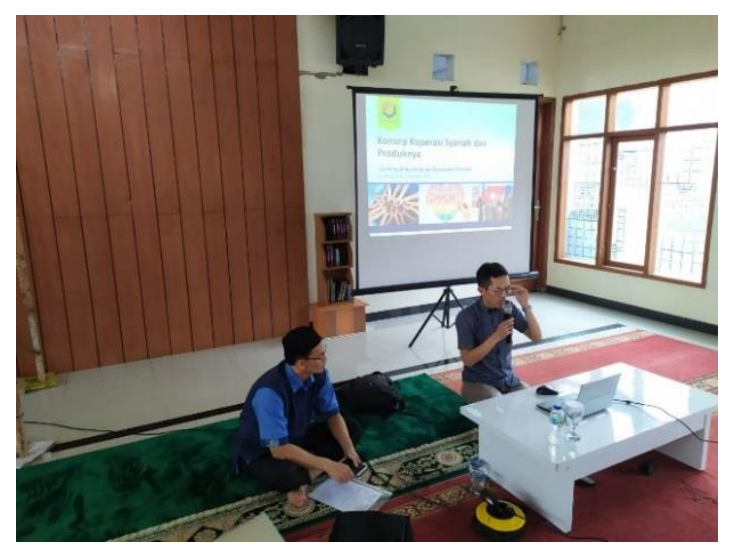

Gambar 2. Penyampaian Materi

Penyajian materi dilakukan dengan metode ceramah dan tanya jawab. Peserta diberi kebebasan untuk bertanya di pertengahan ceramah agar lebih fleksibel dan rasa penasaran peserta bisa langsung terjawab. Para peserta sangat antusias mengikuti kegiatan. Hal ini terlihat dari banyaknya pertanyaan yang disampaikan kepada pemateri. Bahkan banyak dari para peserta yang berharap masih kegiatan tersebut terus berlanjut.

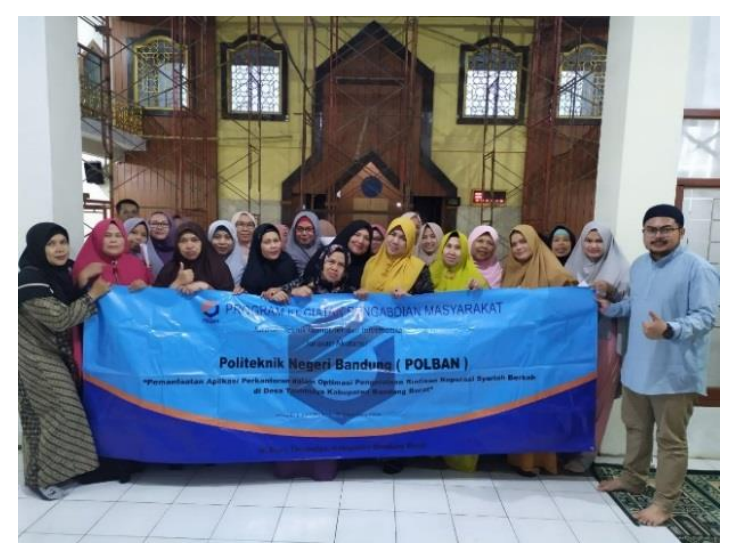

Gambar 3. Akhir Kegiatan

Setelah selesai kegiatan maka selanjutnya dilakukan pengisian kuesioner kembali. Tujuannya untuk mengukur tingkat pemahaman setelah pemberian materi dan diskusi. Untuk bisa melihat perbedaan tersebut, maka dilakukan pengujian statistik pada data yang telah dihimpun, adapun tahap pertama dilakukan pengujian normalitas. Uji normalitas yang digunakan adalah Shapiro-Wilk dan Liliefors. Pengujian normalitas dengan menggunakan Shapiro-Wilk dan Liliefors dianggap uji normalitas yang tepat bila data yang dihimpun berjumlah kecil. Seperti kita ketahui bahwa jumlah peserta hanya 20 orang. Berikut hasil dari uji Shapiro-Wilk dan Liliefors dengan menggunakan bantuan aplikasi SPSS versi 18 .

Tabel 1. Uji Shapiro-Wilk dan Liliefors

\begin{tabular}{lrrrrrr}
\hline & \multicolumn{3}{c}{ Kolmogorov-Smirnov ${ }^{\mathrm{a}}$} & \multicolumn{3}{c}{ Shapiro-Wilk } \\
\cline { 2 - 7 } & Statistic & df & Sig. & Statistic & df & \multicolumn{1}{c}{ Sig. } \\
\hline sebelum & .387 & 20 & .000 & .563 & 20 & .000 \\
sesudah & .262 & 20 & .001 & .733 & 20 & .000 \\
\hline
\end{tabular}

a. Lilliefors Significance Correction

Berdasarkan hasil pengujian pada tabel 1 di atas, dapat diketahui bahwa nilai signi- 
fikansi untuk uji Shapiro-Wilk untuk responden sebelum kegiatan dan setelah kegiatan berada di bawah 5\% sehingga dapat dikatakan bahwa data berdistribusi tidak normal. Hal ini dipertegas melalui uji Liliefors yang mengungkapkan hal yang sama. Pengujian Liliefors merupakan adaptasi dan pengembangan dari Uji Kolmogorov Smirnov. Hasilnya menunjukkan nilai signifikansi responden sebelum kegiatan dan setelah kegiatan berada di bawah 5\% yang artinya seluruh data yang dihimpun tidak berdistribusi normal.

Tahap selanjutnya yang harus dilakukan adalah pengujian komparatif data sebelum dan sesudah kegiatan. Terkait hasil uji normalitas yang menyatakan bahwa data tidak berdistribusi normal, maka uji beda dilakukan dengan menggunakan Wilcoxon Signed Rank Test yang tergolong pada uji nonparametris. Sebelum mendeskripsikan hasil uji Wilcoxon Signed Rank Test, berikut disajikan statistik deskriptif dari data yang telah diujikan.

Tabel 2. Statistik Deskriptif

\begin{tabular}{lrrrrr}
\hline & \multirow{2}{*}{ N } & Mean & $\begin{array}{c}\text { Std. } \\
\text { Deviation }\end{array}$ & Minimum & Maximum \\
\hline sebelum & 20 & 10.1000 & 4.30300 & 8.00 & 22.00 \\
sesudah & 20 & 29.4000 & 3.81686 & 18.00 & 32.00 \\
\hline
\end{tabular}

Berdasarkan statistik deskriptif pada tabel 2 di atas, dapat diketahui beberapa informasi terkait mean, standar deviasi, nilai terbesar, dan nilai terkecil dari masingmasing jawaban responden (peserta) yang berjumlah 20 orang. Nampak bahwa ratarata nilai posttest (setelah kegiatan) lebih besar dari nilai pretest (sebelum kegiatan), yaitu masing-masing 29,40 dan 10,10 . Walaupun secara angka menunjuk- kan perbedaan yang cukup besar, angka tersebut masih harus dibuktikan memiliki makna secara statistik, sehingga dilakukan uji komparasi.

Selanjutnya kita akan melihat hasil uji beda menggunakan Wilcoxon Signed Rank Test. Hasil dari perhitungan Wilcoxon Signed Rank Test disajikan pada tabel di bawah ini.

Tabel 3. Wilcoxon Signed Rank

\begin{tabular}{llrrr}
\hline & & $\begin{array}{c}\text { Mean } \\
\text { Rank }\end{array}$ & $\begin{array}{r}\text { Sum of } \\
\text { Ranks }\end{array}$ \\
\hline sesudah - sebelum & Negative Ranks & $0^{\mathrm{a}}$ & .00 & .00 \\
& Positive Ranks & $20^{\mathrm{b}}$ & 10.50 & 210.00 \\
& Ties & $0^{\mathrm{c}}$ & & \\
& Total & 20 & & \\
\hline
\end{tabular}

a. sesudah $<$ sebelum

b. sesudah $>$ sebelum

c. sesudah $=$ sebelum

Pada hasil Wilcoxon Signed Rank pada tabel 3 di atas dapat diketahui bahwa tidak terdapat negatif rank, atau dengan kata lain nilai posttest selalu lebih besar dibanding nilai pretest untuk setiap peserta. Hal tersebut dipertegas dengan posisi positive rank yang berjumlah 20 orang.

Tabel 4. Wilcoxon Signed Rank Test

\begin{tabular}{lr}
\multicolumn{2}{c}{ Test Statistics $^{\mathbf{b}}$} \\
\hline \multicolumn{2}{c}{ sesudah - sebelum } \\
\hline$Z$ & $-3.927^{\mathrm{a}}$ \\
Asymp. Sig. (2-tailed) & .000 \\
\hline a. Based on negative ranks. & \\
b. Wilcoxon Signed Ranks Test
\end{tabular}

Berdasarkan hasil dari perhitungan Wilcoxon Signed Rank Test pada tabel 4 di atas, maka dapat diketahui bahwa nilai $\mathrm{Z}$ yang didapat sebesar -3,927 dengan $p$ value (Asymp. Sig 2 tailed) sebesar 0,000. Sehingga angka tersebut kurang dari ba- 
tas kritis penelitian 5\% yang bermakna bahwa terdapat perbedaan pemahaman antara kelompok pretest dan posttest atau antara sebelum dilakukan kegiatan dan setelah dilakukan kegiatan.

\section{ULASAN KARYA}

Sebelumnya para peserta belum pernah mendapatkan materi sejenis, baik dari ceramah pada majelis taklim ataupun dari kegiatan lain. Selain itu peserta masih memiliki tingkat literasi yang masih rendah. Adapula dari peserta yang sebelumnya pernah mendengar namun menganggap bahwa produk syariah masih sama dengan produk konvensional. Sehingga mereka antipati terhadap keberadaan konsep maupun produk koperasi syariah. Setelah diberikan pemahaman, barulah mereka sadar terhadap perbedaan yang mencolok antara keduanya.

Kegiatan tersebut belum dilakukan dengan metode praktik agar para peserta dapat langsung melihat contoh form atau aplikasi yang dapat digunakan di koperasi syariah. Sehingga perlu ke depannya dilakukan hal tersebut.

\section{DAMPAK DAN MANFAAT KEGIATAN}

Peserta mendapatkan pengetahuan baru mengenai konsep maupun produkproduk koperasi syariah. Dengan pemahaman baru yang telah disampaikan, maka peserta kegiatan memiliki bekal untuk bisa bergerak mendirikan koperasi syariah atau melakukan konversi koperasi konvensional ke koperasi syariah. Diharapkan mereka dapat menyongsong kemakmuran atau falah secara bersamasama yang dimulai dari gerakan ekonomi.

\section{KESIMPULAN}

Berdasarkan kegiatan Pengabdian Kepada Masyarakat yang telah dilakukan maka dapat ditarik kesimpulan bahwa pemberian edukasi konsep koperasi syariah dan produk-produk koperasi syariah dapat membantu kelompok pengajian untuk lebih memahami bagaimana untuk menggerakkan perekonomian masyarakat sekitar. Para peserta bertekad untuk mulai mengaplikasikan pengetahuan mereka dengan mendirikan koperasi syariah. Peserta pun banyak yang menginginkan untuk diadakannya ceramah yang terjadwal dengan topik-topik yang berkenaan dengan masalah perekonomian. Sehingga mereka bisa memulai memberdayakan perekonomian mereka secara mandiri.

\section{PENGHARGAAN}

Tim pelaksana Pengabdian Kepada Masyarakat menyampaikan terima kasih kepada Politeknik Negeri Bandung yang telah membiayai kegiatan tersebut melalui DIPA-POLBAN 2019. Dengan adanya kegiatan tersebut kami dapat menyebarluaskan ilmu dan pengetahuan yang kami miliki serta dapat menebar kebaikan bagi lingkungan di sekitar Politeknik Negeri Bandung. Semoga kegiatan seperti ini dapat terus dilaksanakan pada tahuntahun berikutnya.

\section{DAFTAR PUSTAKA}

[1] J. Diamant, "The countries with the 10 largest Christian populations and the 10 largest Muslim populations," Pew Research Center, 2019. [Online]. Available:

https://www.pewresearch.org/facttank/2019/04/01/the-countrieswith-the-10-largest-christian- 
populations-and-the-10-largestmuslim-populations/. [Accessed: 04-Jul-2019].

[2] Pew Research Center, "The future of the global muslim population," Pew Research Center, 2011. [Online]. Available: https://www.pewforum.org/2011/0 1/27/the-future-of-the-globalmuslim-population/. [Accessed: 04-Jul-2019].

[3] S. Setiawan and H. A. Mauluddi, "Perilaku Konsumen dalam Membeli Produk Halal di Kota Bandung," At-tijaroh J. Ilmu Manaj. dan Bisnis Islam, vol. 5, no. 2, pp. 232-246, 2019.

[4] D. Suhartanto, C. Gan, I. S. Sarah, and S. Setiawan, "Loyalty towards Islamic banking: service quality, emotional or religious driven?," $J$. Islam. Mark., vol. 11, no. 1, pp. 66-80, 2020.

[5] D. Suhartanto, N. H. Farhani, M. Muflih, and Setiawan, "Loyalty intention towards Islamic Bank: The role of religiosity, image, and trust," Int. J. Econ. Manag., vol. 12, no. 1, pp. 137-151, Jun. 2018.

[6] T. Zhuharon, "Mungkinkah Muslim Miskin dan Non Muslim Konglomerat, Bersatu dalam Ekonomi?," Cendana News, 2018. [Online]. Available: https://www.cendananews.com/20 18/06/mungkinkah-muslimmiskin-dan-non-muslimkonglomerat-bersatu-dalamekonomi.html.
[7] M. Syafar, "Pemberdayaan Komunitas Taklim di Kelurahan Banten Kecamatan Kasemen Kota Serang," Lembaran Masy. J. Pengemb. Masy. Islam, vol. 1, no. 1, pp. 41-68, 2015.

[8] Suriati, "Efektifitas Pengajian Rutin dalam Meningkatkan Perilaku Beragama Masyarkat," Al-Mishbah, vol. 11, no. 1, pp. 117-150, 2015.

[9] Sugito and S. Julaeha, "Pemberdayaan Ekonomi dan Korelasinya Terhadap Kualitas Beragama," J. Bimas Islam, vol. 9, no. 3, pp. 405-444, 2016.

[10] A. S. Hidayat, "Membangun Dimensi Baru Dakwah Islam: Dari Dskwah Tekstual menuju Dakwah Kontekstual," J. Risal., vol. 24, no. 2, pp. 1-15, 2013.

[11] F. Sulmaihati, "Pertumbuhan Industri Keuangan Syariah hingga Mei 2019 Melambat," Kata Data, 2019. [Online]. Available: https://katadata.co.id/berita/2019/0 8/07/pertumbuhan-industrikeuangan-syariah-hingga-mei2019-melambat.

[12] radartegal.com, "Mayoritas Muslim, Ekonomi Islam Tetap Sulit Kuasai Perbankan di Indonesia," Radar Tegal, 2019. [Online]. Available: https://radartegal.com/beritaekonomi/mayoritas-muslimekonomi-islam-tetap-sulitkuasai.34390.html. 